\title{
Demonstration of cytoplasmic structural proteins in developing enamel matrix of the rat incisor
}

\author{
Mitsuo Kakei and Hiroshi Nakahara \\ First Department of Oral Anatomy, Josai Dental University, 1-1, Keyakidai, \\ Sakado, Saitama 350-02, Japan
}

[Accepted for publication: June 20, 1985]

\begin{abstract}
Key words: enamel matrix proteins/cytoskeletal proteins/troponin subunits/actin / myosin light chains
\end{abstract}

\section{Introduction}

The extracelluar matrix of developing dental enamel is characterized by two classes of proteins. One is comprised of hydrophobic proteins, termed amelogenins, which show distinctive amino acid compositions and progressive loss during the maturation stage of enamel ${ }^{1-3}$. The other contains acidic proteins, termed enamelins, which have a higher concentration of acidic amino acids, relatively high molecular weight, and a tendency to remain during the maturation stage of enamel ${ }^{4)}$.

Recently, we clearly demonstrated by means of an immunological technique that amelogenins contain carbonic anhydrase (CA) and its degradation products as a major component ${ }^{5}$. We also proposed that the function of this enzyme is to supply carbonate ions at the sites of crystal nucleation of developing enamel, dentin, as well as bone ${ }^{6-9)}$. However, the biological characteristics and functions of enamel matrix proteins are not yet completely clear. On the other hand, our recent TEM studies demonstrated the presence of an organic envelope which may control the formation of crystallites in developing enamel, dentin, as well as in bone, prior to crystal growth ${ }^{9-11}$. Accordingly we speculated that the organic matrices directly relating to mineral formation (chiefly the organic envelope) of all these hard tissues are composed of similar proteins. And we also proposed that these proteins may pos- sibly be derived from rather widely distributed substances in biological systems. Based on this concept, the present study was undertaken to determine whether or not some cytoplasmic structural proteins are contained in the enamel matrix during its development.

\section{Materials and Methods}

Preparation of enamel samples: Lower incisors were dissected from anesthetized adult Sprague-Dawley rats. After the reincisors were rinsed with cold saline. Sammoval of the surrounding soft tissues, the ples of developing enamel from early (matrix-formation), middle (transitional) and late (maturation) stages were excised with a razor blade from root apex, middle, and white opaque regions, respectively. Whole enamel sample containing these three regions, as well as EDTA-soluble and -insoluble samples of whole enamel, were also prepared as described previously ${ }^{5)}$. These samples were first subjected individually to $12 \%$ SDS polyacrylamide gel electrophoresis. After electrophoresis, the proteins were transferred to nitrocellulose sheets $(0.45 \mu \mathrm{m}$, Schleicher and Schüll, W. Germany) using an electroblotting apparatus (KS-8450 GMT, Marysol Industry Co. Ltd., Japan). Electroblotting was carried out for $3 \mathrm{~h}$ at $180 \mathrm{~mA}$.

Preparation of antibodies specific for troponin $\mathrm{T}(\mathrm{Tn}-\mathrm{T})$, troponin $\mathrm{I}(\mathrm{Tn}-\mathrm{I})$, actin, and myosin: Antiserum specific for myosin was purchased from Miles Yeda Ltd. Tn-T and $\mathrm{Tn}-\mathrm{I}$ were prepared from rat skeletal 
muscle by the method of Ebashi, Wakabayashi and Ebashi ${ }^{12)}$. Actin was prepared from rat skeletal muscle by the methods of Straub $^{13)}$ and Mommaerts ${ }^{14)}$. Tn subunits and actin were purified by electrophoresis and prepared individually for use as antigens. White rabbits, weighing $2.5 \mathrm{~kg}$, were injected subcutaneously with $3-5 \mathrm{mg}$ of antigen mixed in Freund's complete adjuvant. Immunoglobulin G (IgG) was fractionated from whole antiserum by ammonium sulfate precipitation and Protein A-Sepharose chromatography.

Immunological detection of proteins on nitrocellulose filters: After electrophoretic blotting on nitrocellulose membrane filters, the filters were rinsed with T-TBS $(20 \mathrm{mM}$ Tris, $50 \mathrm{mM} \mathrm{NaCl}, 0.05 \%$ Tween $20, \mathrm{pH}$ 7.5 ) for $20 \mathrm{~min}$, followed by drying at room temperature. The filters were then incubated in $3 \%$ gelatin-TBS for $1 \mathrm{~h}$ at $45^{\circ} \mathrm{C}$. Antibodies specific for $\mathrm{Tn}-\mathrm{T}$, Tn-I, actin, and myosin were diluted 3,000-fold with $1 \%$ gelatin-TBS. The membrane filters were incubated with each primary antibody solution at room temperature for $2 \mathrm{~h}$. The membrane filters were then rinsed with $\mathrm{T}$ TBS for $30 \mathrm{~min}$. The anti-rabbit IgG goat serum (Japan Immunoresearch Labs. Co. Ltd.), which was diluted 2,000-fold with $1 \%$ gelatin-TBS, was used as the second antibody, and the filters were incubated in it for $1 \mathrm{~h}$ at room temperature, followed by a 30-min rinse with T-TBS. Next the membrane filters were incubated for $1 \mathrm{~h}$ at room temperature with a rabbit peroxidase-antiperoxidase complex reagent (Miles Labs.) which was diluted 2,000 -fold in $1 \%$ gelatinTBS, and then they were rinsed with T-TBS for $30 \mathrm{~min}$. For the color reaction, the filters were immersed in a mixture containing $40 \mathrm{ml}$ $0.05 \mathrm{M}$ Tris-HCl, pH 7.4, $10 \mathrm{mg} \mathrm{3-3-di-}$ aminobenzidine tetrahydrochloride (Sigma), and $10 \mu \mathrm{l} 30 \% \quad \mathrm{H}_{2} \mathrm{O}_{2}$. The reaction was terminated after $20 \mathrm{~min}$ by washing with distilled water.

\section{Results}

Immunoblotting patterns obtained by using the specific antibodies are shown in
Fig. 1. A group of major bands, 25k-30k daltons, showed a distinctly positive reaction with all these antibodies in the early, middle, whole, and EDTA-treated enamel samples. And a proportionally smaller group of heavier bands, approximately $35 \mathrm{k}-50 \mathrm{k}$ daltons, gave a clearly positive reaction with anti-Tn-T, anti-Tn-I, and anti-actin in these samples, whereas these bands were negative when treated with anti-myosin (Fig. 1). A relatively strong reaction with anti-Tn-T was observed in the $30 \mathrm{k}$ dalton band of these samples. Furthermore, this positive band showed a wider zone compared with that using anti-CA and other antibodies (Fig. 1). In the late stage, there remained three major bands, $25 \mathrm{k}, 28 \mathrm{k}$, and $29 \mathrm{k}$ daltons, and two slight bands, $30 \mathrm{k}$ and $28.5 \mathrm{k}$ daltons, which gave a positive reaction with anti- $\mathrm{Tn}-\mathrm{T}$, anti-Tn-I, and anti-actin. However, a small band of $30 \mathrm{k}$ dalton was negative with antimyosin in this stage (Fig. 1a). The 25k, $28 \mathrm{k}$, and $29 \mathrm{k}$ dalton bands of late stage sample showed more clearly positive reactions against anti-actin and anti-myosin compared with those with anti-Tn-T and anti-Tn-I (Fig. 1a). A group of low molecular weight bands, $14 \mathrm{k}-23 \mathrm{k}$ daltons, also showed a slightly positive reaction with anti-Tn-T and antiTn-I in all these samples. In the EDTAsoluble sample, a $14 \mathrm{k}$ dalton band showed a strongly positive reaction with anti-Tn-T (Fig. 1b). Using anti-actin and anti-myosin, $14 \mathrm{k}$ and $16 \mathrm{k}$ dalton positive bands were observed in the middle, late, and EDTA-insoluble samples. However, the intensity and position of reaction in these bands against anti-actin and anti-myosin were different; the $16 \mathrm{k}$ dalton band showed a stronger positive reaction with anti-actin than with antimyosin, while the $14 \mathrm{k}$ dalton one showed an obviously positive reaction with anti-myosin.

\section{Discussion}

In the present study, using antibodies specific for Tn-T, Tn-I, actin and myosin, we showed that distinctly positive bands could be detected in all the enamel samples. In these enamel samples, we also demonstrated that most of the bands ranging in 
size from low molecular weight to approximately $50 \mathrm{k}$ daltons were closely related with each other in composition. In these positively reacting bands, the amino acid pattern of the heavier proteins ${ }^{12,15)}$ (more than $30 \mathrm{k}$ ) were remarkably different from that of CA which has some resemblance to amelogenin. Actin and myosin showed a tendency to remain at the late (maturation) stage more than did Tn-T and Tn-I. These proteins are generally considered to be ubiquitous substances in both muscle and nonmuscle cells, and their amino acid composition and molecular weight are well established ${ }^{12,15)}$. However, the amino acid compositions of troponin, actin and myosin are dissimilar to that of amelogenin. These lines of evidence indicate that CA is a major component of amelogenin.

It is well known that muscle myosin contains two heavy chains, approximate $200 \mathrm{k}$ daltons, and some light chains, $16 \mathrm{k}-27 \mathrm{k}$ daltons; however, in this study a positive reaction was observed only in the band with a molecular weight corresponding to that of myosin light chains. It is also interesting to note that both major $(25 \mathrm{k}-30 \mathrm{k})$ and low molecular weight bands reacted positively with anti-actin. This fact suggests that enamel contains small actin-derived peptides which are associated closely with other proteins. It has also been reported that the amino acid composition of matrix proteins of mature enamel are rich in aspartic acid, glycine, glutamic acid, and alanine ${ }^{1,4)}$. This composition is rather similar to that of myosin light chains and actin which also remain in the late (maturation) stage.

The results of the present study suggest that some cytoplasmic structural proteins are involved in the formation of the enamel matrix. During matrix formation, these proteins are supposedly altered by a complicated process of degradation and recombination. These proteins are probably derived from ameloblasts; however, the exact source of the substances and their role in the calcification process remain as problems for further study.

\section{References}

1) Eastoe, J. E.: The amino acid composition of proteins from the oral tissues-II, The matrix proteins in dentine and enamel from developing human deciduous teeth. Arch. Oral Biol. 8: 633-652, 1963.

2) Eastoe, J. E.: Enamel protein chemistry-past, present and future. J. Dent. Res. 58(B): 753-763, 1979.

3) Robinson, C., Briggs, H. D., Atkinson, P. J. and Weatherell, J. A.: Matrix and mineral changes in developing enamel. J. Dent. Res. 58(B) : 871-880, 1979.

4) Termine, J. D., Belcourt, A. B., Christner, P. J., Conn, K. M. and Nylen, M. U.: Properties of dissociatively extracted fetal tooth matrix proteins. 1. Principal molecular species in developing bovine enamel. J. Biol. Chem. 255: 9760-9768, 1980.

5) Kakei, M. and Nakahara, H.: Electroimmunoblotting study of carbonic anhydrase in developing enamel and dentin of the rat incisor. Jpn. J. Oral Biol. 27: 357-361, 1985.

6) Kakei, M. and Nakahara, H.: A light microscopic study of the localization of carbonic anhydrase activity in the developing dentin and enamel of the rat lower incisor. Jpn. J. Oral Biol. 25: 374-377, 1983.

7) Kakei, M. and Nakahara, H.: Ultrastructural localization of carbonic anhydrase activity in developing enamel and dentin of the rat incisor. Jpn. J. Oral Biol. 25: 1129 1133, 1983.

8) Kakei, M. and Nakahara, H.: Histochemical localization of carbonic anhydrase in epiphyseal growth cartilage and calvaria of the rat. Jpn. J. Oral Biol. 26: 554-558, 1984.

9) Nakahara, H. and Kakei, M.: Central dark line and carbonic anhydrase: Problems relating to crystal nucleation in enamel. In: Tooth Enamel IV (Fearnhead, R. W. and Suga, S., ed.), p. 42-46, Elsevier. Science Publishers B.V., 1984.

10) Nakahara, H. and Kakei, M.: The central dark line in developing enamel crystallite: An electron microscopic study. Bull. Josai Dent. Univ. 12(1): 1-7, 1983.

11) Nakahara, H. and Kakei, M.: TEM observations on the crystallites of dentin and bone. Bull. Josai Dent. Univ. 13(2): 259-263, 1984.

12) Ebashi, S., Wakabayashi, T. and Ebashi, F.: 
Troponin and its components. J. Biochem. 69: 441-445, 1971.

13) Straub, F. B.: Actin. Stud. Inst. Med. Chem., Univ. Szeged. Hung. 2: 3-15, 1942.

14) Mommaerts, W. F. H. M.: Reversible polymerization and ultracentrifugal purification of actin. J. Biol. Chem. 118: 559-565, 1951.

15) Kominz, D. R., Hough, A., Symonds, P. and Laki, K.: The amino acid composition of actin, myosin, tropomyosin and the meromyosin. Arch. Biochem. Biophys. 50: 148159, 1954.

Fig. 1 Electrophoretic blotting of SDS polyacrylamide gel using antibodies specific for troponin- $\mathrm{T}(\mathrm{T})$, troponin-I $(\mathrm{I})$, actin $(\mathrm{Ac})$, and myosin $(\mathrm{My})$. Carbonic anhydrase (CA) was prepared by the method reported previously ${ }^{5}$. AB: Amido black staining. (a): Developing enamel matrix proteins of each stage (E: Early, M: Middle, and L: Late). (b): Enamel matrix proteins of whole (W), EDTA-soluble (EDTA-S), and EDTA-insoluble (EDTA-INS) samples. 


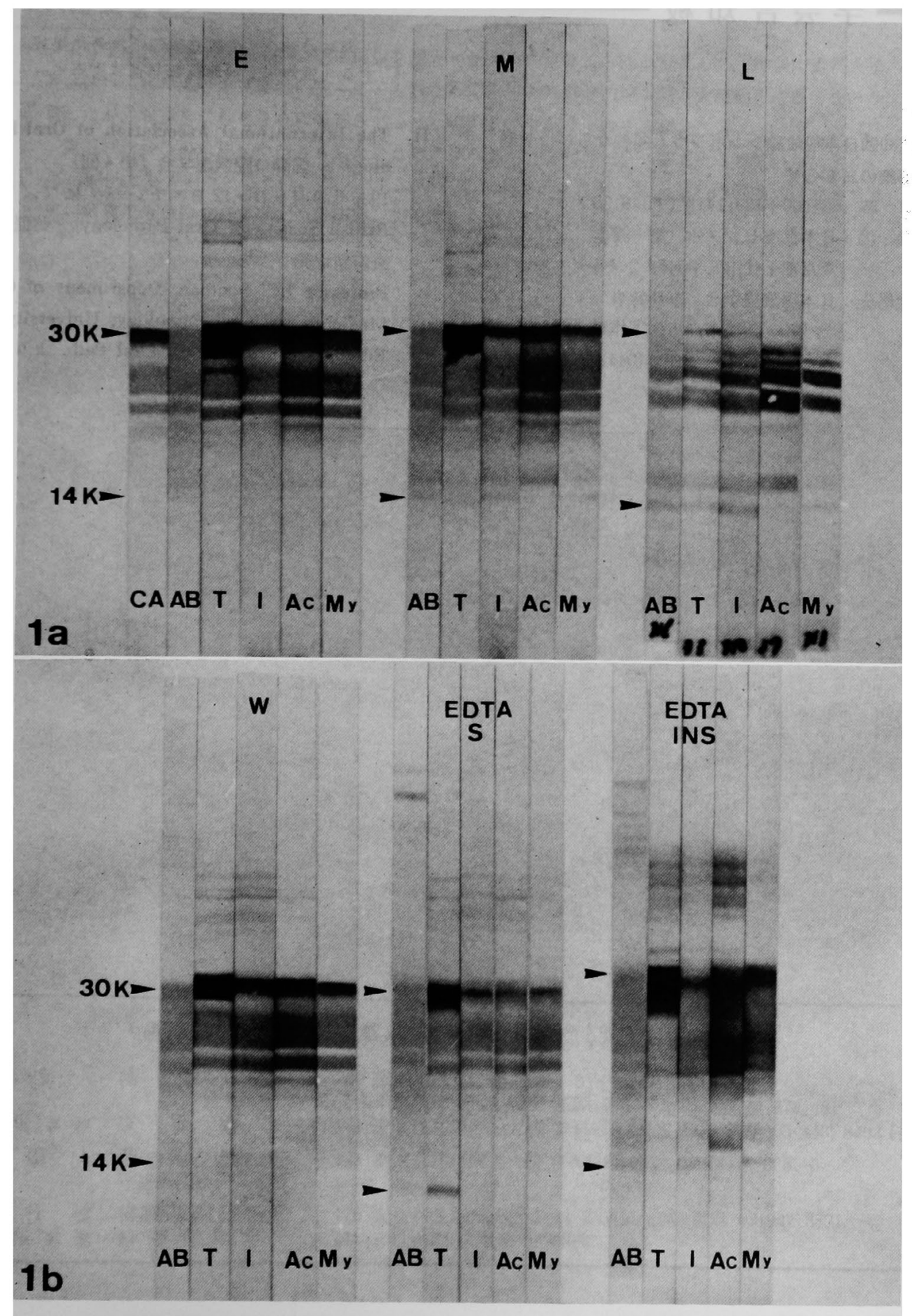

